\title{
Precisão de movimento em robôs microcontrolados
}

\section{Motion accuracy in microcontrolled robots}

DOI: $10.46814 / \operatorname{lajdv3n1-042}$

Recebimento dos originais: 30/10/2020

Aceitação para publicação: 23/12/2020

\author{
Bruno Ferreira Jorge \\ Mestre em Tecnologias Aplicadas à Saúde \\ IFMG - Instituto Federal De Minas Gerais \\ Campus Ibirité - CEP 32407-197 - Ibirité MG \\ E-mail: bruno.jorge@ifmg.edu.br \\ Carlos Roberto de Oliveira Souza \\ Mestre em Administração \\ Universidade De Itaúna - Faculdade De Engenharia \\ Caixa Postal 100 - Itaúna MG \\ E-mail: carlosrosouza@gmail.com
}

\section{RESUMO}

Este trabalho tem como objetivo principal verificar a viabilidade técnica da utilização de microcontroladores no controle de posicionamento de um robô autônomo. Foi implementado um robô com a função de fazer um trajeto pré- definido, apresentando repetibilidade e precisão de movimento. Para executar essas tarefas foram confeccionadas placas eletrônicas para controle de drives e motores de passo, além de uma programação específica.

Palavras Chaves: microcontroladores, repetibilidade, programação, motores de passo, drives.

\section{ABSTRACT}

This work has as main objective to verify the technical feasibility of the use of microcontrollers in control of an autonomous robot. One set up a robot with the function of making a pre-defined path, with repeatability and precision of movement. To perform these tasks, electronic boards were made to control stepper motors and drives, as well as a program

Keywords: microcontrollers, repeatability, program, stepper motors, drives.

\section{INTRODUÇÃO}

Há muitas décadas o homem tem um intenso desejo de construir máquinas que reproduzam ações humanas e desde então tem ampliado seus conhecimentos e domínio na área de robótica.

A evolução da robótica acompanha a evolução da informática e da eletrônica. Os robôs são programados, ou seja, funções pré- definidas são programadas via softwares e executadas via hardware. 
Alguns sistemas necessitam de um controle muito preciso, principalmente no quesito posicionamento e repetibilidade. Para atender esses objetivos, são utilizados sistemas de controle complexos e de custo elevado, uma vez que é difícil alcançar tais objetivos quando se trata do uso de microcontroladores.

A proposta desse trabalho consiste na construção de um robô móvel, utilizando um microcontrolador PIC. Esse robô deve fornecer o máximo de precisão em seu posicionamento.

\section{ROBÓTICA}

Um robô móvel é um dispositivo mecânico montado sobre uma base não fixa, que age sob o controle de um sistema computacional, equipado com sensores e atuadores que o permitem interagir com o ambiente (Pieri, 2002).

\subsection{ATUADORES}

Os atuadores colocam em prática as tarefas ordenadas pelo sistema de controle. São responsáveis pelo movimento e articulação das partes móveis do sistema (Pieri 2002).

Podem ser classificados em função da energia que utilizam para funcionarem.

Os três principais tipos de atuadores são pneumáticos, hidráulicos e elétricos.

Na robótica industrial e móvel, os atuadores elétricos são os mais comuns e utilizados, pois apresentam ótimas características de controle, sensibilidade, precisão e confiabilidade.

\subsection{MOTORES DE PASSO}

O motor de passo é um tipo de motor elétrico usado quando um movimento exige precisão ou quando deve ser rotacionado em um ângulo exato (Silva, 2006).

Silva, 2006 coloca três modos de acionamentos distintos para os motores de passo:

Modo Wave Drive - Uma bobina do motor é acionada a cada vez de modo seqüencial, obtendo um movimento com passo de $90^{\circ}$.

Modo Full Step Drive - Duas bobinas são energizadas ao mesmo tempo o que resulta um torque muito mais alto com a desvantagem de alto consumo de corrente pelo motor.

Modo Half Step Drive - Consiste na combinação dos dois modos anteriores, tendo como vantagem o movimento do motor com meio passo, o que garante uma maior precisão. 


\subsection{MICROCONTROLADOR PIC 18F452}

O microcontrolador é um circuito integrado programável semelhante a um computador, possuindo memórias, portas de entrada e saídas sistema de controle de tempo interno e externo e outros (Silva, 2006).

O microcontrolador pode ser usado para controle específico ou pode estar incluído em unidades de controle para os mais diversos sistemas, tais como: máquinas pneumáticas e hidráulicas comandadas, motores, temporizadores, sistemas autônomos de controle, automóveis, entre outros.

Para o desenvolvimento do projeto, utilizou-se o PIC18F452.

\section{CARACTERÍSTICAS DO ROBÔ DESENVOLVIDO}

O robô desenvolvido neste trabalho tem o objetivo de executar um trajeto com o máximo de precisão e repetibilidade. Para a realização de suas funções, o robô utiliza motores de passo e drives para o controle dos mesmos. O robô não utiliza sensores, uma vez que o controle do trajeto é realizado apenas por dados previamente gravados na memória do microcontrolador.

O funcionamento do robô se baseia no envio de dados do microcontrolador para os drives. Esses drives realizam o controle dos motores de passo.

\subsection{MOTORES E DRIVES}

Para a locomoção do robô, foram utilizados os motores de passo HV341-01-FL da PARKER (Figura 1). Entre muitas vantagens destacam-se um torque de $38,8 \mathrm{kgf.cm}$ e um ângulo de passo de $1.8^{\circ}$.

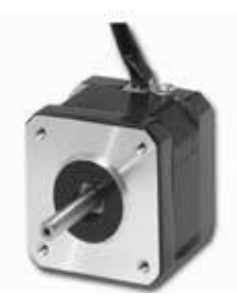

Figura 1 - Motor de passo HV341-01-FL

Para o controle dos motores de passos, foram utilizados drives da Parker, modelo OEM750 (Figura 2). Esse drive possui possibilidades para configuração da sua resolução, que pode variar de 200 até 50800 ppr (passos por rotação) garantindo uma resolução em graus que pode variar de 1.8 a 0.00708 graus por pulso, tornando o deslocamento do robôo muito preciso. Utilizando esse drive, é possível chegar a uma grande velocidade sem a perda significativa do torque se comparado com o acionamento do motor sem o drive. 


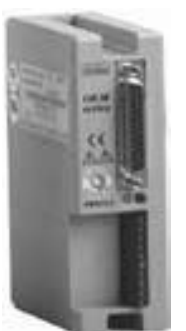

Figura 2 - Drive OEM750

Quanto maior a velocidade do motor, menor é o seu torque. Na Figura 3, é possível verificar o desempenho do motor de passo quando controlado pelo drive OEM750.

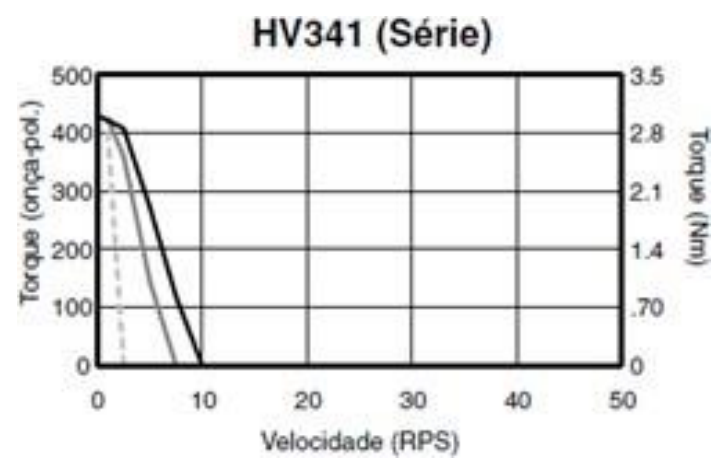

Figura 3 - Desempenho do motor controlado pelo drive OEM750

Para ligar os motores, foi realizada uma ligação em série. Essa configuração foi escolhida devido à ligação em paralelo, apesar de oferecer um maior torque, apresentar correntes de pico e de trabalho muito altas.

\subsection{MONTAGEM MECÂNICA}

O projeto possui um sistema de transmissão por acoplamento direto da roda ao eixo do motor. Esse sistema possui a vantagem de possuir uma fácil montagem, uma boa precisão e ganho de espaço se comparado com outros sistemas de acoplamento como sistemas por engrenagens ou via correias.

Cada motor de passo é acoplado a uma roda de alumínio de $115 \mathrm{~mm}$ de raio. Essas rodas foram usinadas exclusivamente para diminuir a área em contato com o solo. Para adquirir um bom equilíbrio, utilizou-se uma roda esférica como terceiro ponto de apoio, permitindo um deslocamento em qualquer direção horizontal com um mínimo de esforço, o que torna a perda por atrito mínima. A estrutura física do robô pode ser vista na Figura 4. 


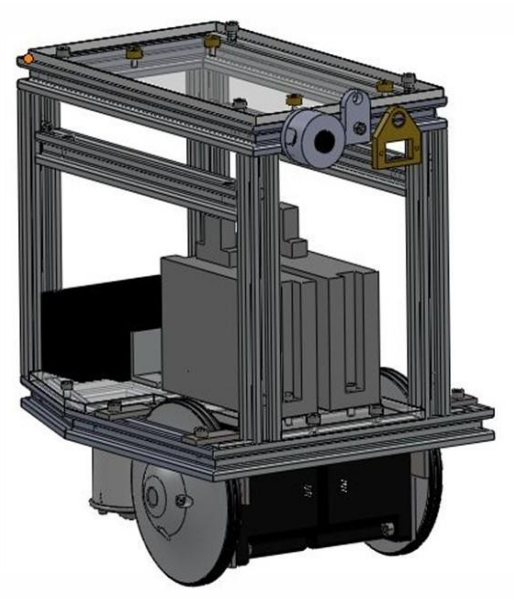

Figura 4 - Estrutura física do robô

\subsection{MONTAGEM ELETRÔNICA}

O circuito eletrônico do robô é responsável por efetuar a comunicação entre todos os equipamentos utilizados no projeto. Foram confeccionadas duas placas eletrônicas: uma placa principal e outra placa para o circuito de controle dos drives.

Para confecção das mesmas, foi utilizado o software Eagle, versão 4.16.

Segundo Carvalhosa \& Leite, 2006, os sistemas robóticos podem conviver com limitações de mobilidade devido à sua fonte de energia ser externa. Os robôs de maior autonomia não podem, porém, ter cabos que os liguem permanentemente ao exterior. Deste modo, o robô precisa ter alguma forma capaz de armazenar ou produzir energia para seu funcionamento.

A fonte de energia escolhida para este projeto é composta por baterias de Lítio-Polímero. O uso desse tipo de bateria é adequado, devido à sua grande capacidade de armazenamento de energia, além de serem muito leves e compactas. Utilizou-se duas baterias no robô: uma para alimentação do circuito do microcontrolador e uma para alimentação dos drives de controle.

\subsubsection{Placa do microcontrolador}

A Figura 9 mostra a placa do microcontrolador. Para alimentação do microcontrolador, utilizou-se uma fonte de $5 \mathrm{~V}$. Como a bateria utilizada é de $11,11 \mathrm{~V}$, foi necessário utilizar um regulador de tensão (7805) fornecendo uma tensão fixa de 5V. Percebe-se também a existência de um LED, que indica a energização do circuito. No pino 1 do microcontrolador (MCLR), foi utilizado um botão com objetivo de reinicializar o microcontrolador. Os pinos 13 e 14 foram utilizados para o oscilador externo de $20000 \mathrm{MHz}$, que caracteriza a velocidade de processamento de dados do microcontrolador. Os demais pinos foram ligados em conectores diversos, com o objetivo de comunicar com outras placas externas. No projeto, utilizou-se uma placa externa para controle dos drives. Muñoz et al 2006 também utilizou uma arquitetura expansível, de tal maneira que permite 
adaptar módulos adicionais de atuadores sensores, e outros dispositivos de hardware. A placa do microcontrolador pode ser visualizada na Figura 5.

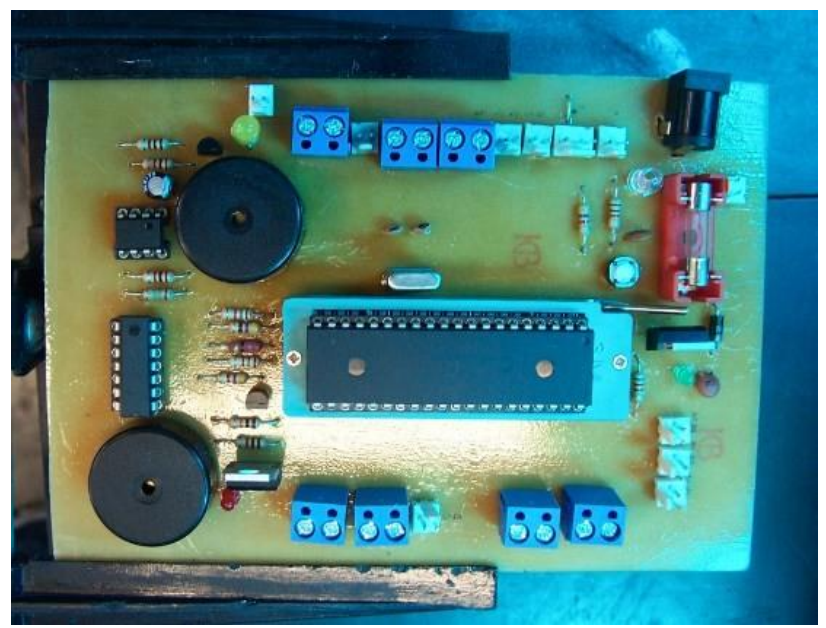

Figura 5 - Placa do microcontrolador

Conforme especificações do fabricante, a tensão na bateria de lítio-polímero de 11,1V não pode ser inferior a 9V. Para monitorar a tensão da bateria foi utilizado um circuito que consiste no uso de um amplificador operacional que compara a tensão da bateria com uma tensão de referência. Deste modo, sempre que a tensão for inferior a 9,4V aciona-se um LED e um buzzer, indicando que a bateria necessita ser recarregada.

Sempre que o circuito da placa do microcontrolador é energizado, um buzzer e um LED são acionados e ficam ativados de forma intermitente, indicando o funcionamento do robô. Esse circuito foi desenvolvido de forma independente, utilizando um temporizador 555.

\subsubsection{Placa dos drives}

Essa placa é responsável pela alimentação dos drives e envio dos sinais dos mesmos para o funcionamento dos motores de passo.

Para o funcionamento da placa, foi utilizada uma bateria de lítio-polímero de 22,2V para alimentação dos drives. Essa bateria não pode ter tensão inferior a $18 \mathrm{~V}$. Portanto foi utilizado um circuito comparador para a bateria. Caso a tensão da mesma seja inferior a $18,4 \mathrm{~V}$, aciona-se um LED e um buzzer, indicando que a bateria necessita ser recarregada. A placa também permite o uso de duas baterias de 22,2V em série, resultando em uma tensão total de 44,4V. O uso de duas baterias em série garante um torque maior ao robô.

Para envio de dados dos drives aos motores, foram utilizados dois conectores DB9. A Figura 6 mostra a placa dos drives. 


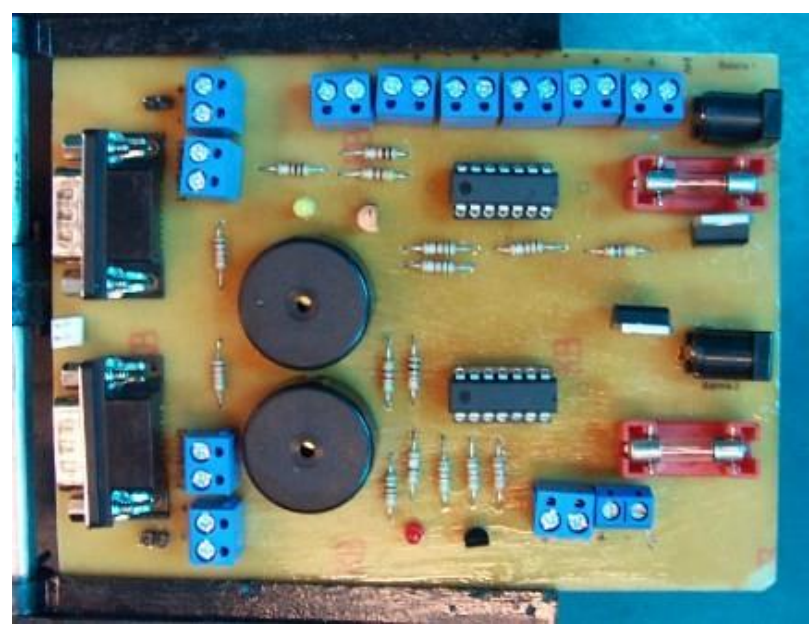

Figura 6 - Placa dos drives

\section{DESENVOLVIMENTO DO PROGRAMA}

A linguagem utilizada para programação do projeto foi a linguagem $\mathrm{C}$, apresentando grande confiabilidade, regularidade, simplicidade, facilidade de uso e material didático simples e eficaz.

Para compilação do programa em linguagem de máquina, o software utilizado foi o PCWH, versão 4.104, da empresa CCS. O software usado na gravação do microcontrolador foi o MPLAB, versão 8.10, da empresa Microchip, programa que é facilmente integrado ao PCWH.

No início do programa foi definido o microcontrolador utilizado e as configurações do mesmo. A Figura 7 mostra definições para o programa. dispositivos de hardware.

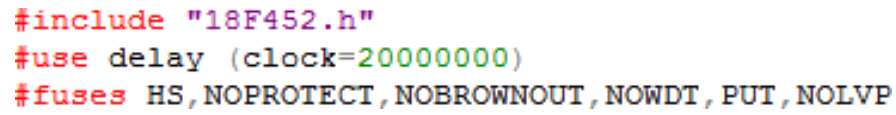

Figura 7 - Definições do Programa

A primeira linha se trata de um arquivo padrão da Microchip para o PIC 18F452 que possui uma série de definições necessárias para a utilização de microcontroladores. A segunda linha define a freqüência do oscilador utilizado no projeto $(20 \mathrm{MHz})$. A terceira linha define algumas opções para a utilização do microcontrolador. Essas opções são descritas a seguir:

- HS - Utilizado para o uso de osciladores externos com freqüências elevadas (acima de $4 \mathrm{MHz})$.

- NOPROTECT - Proteção de leitura desativada. Permite que qualquer pessoa possa ler o programa gravado no microcontrolador PIC.

- NOBROWNOUT - Brown Out desativado. Garante que o microcontrolador não reinicie automaticamente caso a tensão de alimentação seja menor que $4 \mathrm{~V}$.

- NOWDT - Watchdog Timer desativado. Desativa um contador interno que reiniciaria o 
programa toda vez que esse contador estoura-se.

- PUT - Power Up Timer ativado. Faz com que o PIC só comece a operar cerca de 72 ms após o pino MCLR ser colocado em nível alto.

- NOLVP - Low Voltage Program desativado. Caso essa opção fosse ativada, o PIC poderia ser gravado em baixa tensão (5V), porém o pino 10 (RB4), passaria a operar exclusivamente para o uso na gravação.

As definições das variáveis utilizadas no programa são demonstradas na Figura 8.

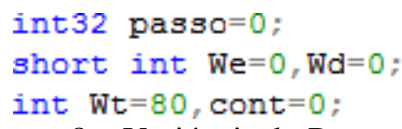

Figura 8 - Variáveis do Programa

A variável passo é do tipo int32 e é utilizada para definir qual a distância percorrida pelo robô. Sua faixa de valores varia de 0 a 4.294.967.295.

As variáveis We,e Wd são do tipo short int e assumem valor 0 ou o valor 1. São usadas para definição dos motores que entrarão em funcionamento.

A variável Wt é do tipo int e define a velocidade do robô. Ela é responsável pelo tempo de parada (em microssegundos) entre o nível alto e o nível baixo do pulso enviado aos drives. A Figura 9 mostra a função principal do programa.

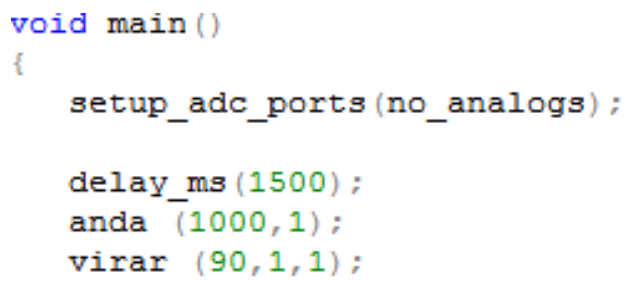

Figura 9 - Função principal

A terceira linha, setup_adc_ports(no analogs), define que os pinos do PIC não serão utilizados para entradas ou saídas analógicas.

O trecho colocado possui uma linha da seguinte forma: anda $(1000,1)$. Trata-se de uma função chamada pelo programa principal. O número 1000 indica a distância que o robô irá deslocar em linha reta (em mm) e o algarismo 1 indica qual o sentido de rotação dos motores, no caso, para frente. Caso o algarismo fosse 0 , os motores teriam a rotação invertida.

Outra linha existente no trecho possui o seguinte texto: virar $(90,1,1)$. O número 90 indica quantos graus o robô irá virar, o segundo algarismo (1), indica o sentido de rotação do motor (se fosse 
o algarismo 0, o sentido de rotação seria invertido) e o terceiro algarismo (1), indica que apenas a roda direita irá funcionar, sendo que a esquerda ficará parada. Isso faz com que o robô vire para a esquerda Caso o terceiro algarismo fosse 2, apenas a roda esquerda do robô entraria em funcionamento. Colocando o terceiro algarismo assuma o valor 3, os dois motores atuam em sentidos contrários, fazebdi o robô girar a quantidade de graus desejada sobre seu próprio eixo.

Com a construção das funções anda e virar, o programa principal se tornou muito mais fácil de trabalhar.

\section{TESTES E ANÁLISE DOS RESULTADOS}

Os materiais utilizados, assim como a confecção do robô e seus testes foram realizados no laboratório de automação da unidade do SENAI (Serviço Nacional de Aprendizagem Industrial) de Pará de Minas - MG. Foram realizados testes de navegação com diversos programas simples, fazendo o robô virar para os lados, andar para frente e andar para trás, garantindo a correta ligação entre as placas, drives e motores. Com os testes de navegação, foi possível verificar sentidos de giro dos motores e o tempo de intervalo entre o envio de pulsos aos drives.

Foram realizados testes de precisão de movimento e repetibilidade com velocidades diferentes, determinando assim a velocidade que o projeto iria trabalhar. Percebeu-se que em velocidades muito altas, havia um deslocamento incorreto antes de o robô entrar em movimento, o que o tirava da posição de alinhamento. Além de oferecer uma perda de torque aos motores do robô, em alta velocidade, o mesmo não apresentou nenhuma precisão de movimento.

Com velocidades mais lentas, houve uma grande evolução na precisão do projeto, porém sua repetibilidade ainda não estava atendendo ao objetivo do trabalho.

Quando o tempo de parada entre os pulsos enviados aos drives foi superior a $70 \mu$ s, o robô passou a desempenhar sua função de forma correta, apresentando precisão de movimento e repetibilidade.

Tempos de parada entre $70 \mu$ s e $140 \mu$ s apresentaram o mesmo desempenho de precisão e repetibilidade. Decidiu-se trabalhar com um tempo de parada entre o envio de pulsos aos drives de $80 \mu$ s, alcançando assim o objetivo do projeto.

Com os sinais de controle funcionando corretamente, foram testados os movimentos de conversão do robô em diversos trajetos diferentes, virando à direita, virando à esquerda, girando sobre o próprio eixo. Enfim, vários testes foram realizados, em diversos trajetos diferentes, com o objetivo principal de definir os parâmetros principais da programação, principalmente a velocidade do robô. A Figura 10 mostra o robô pronto para navegação. 


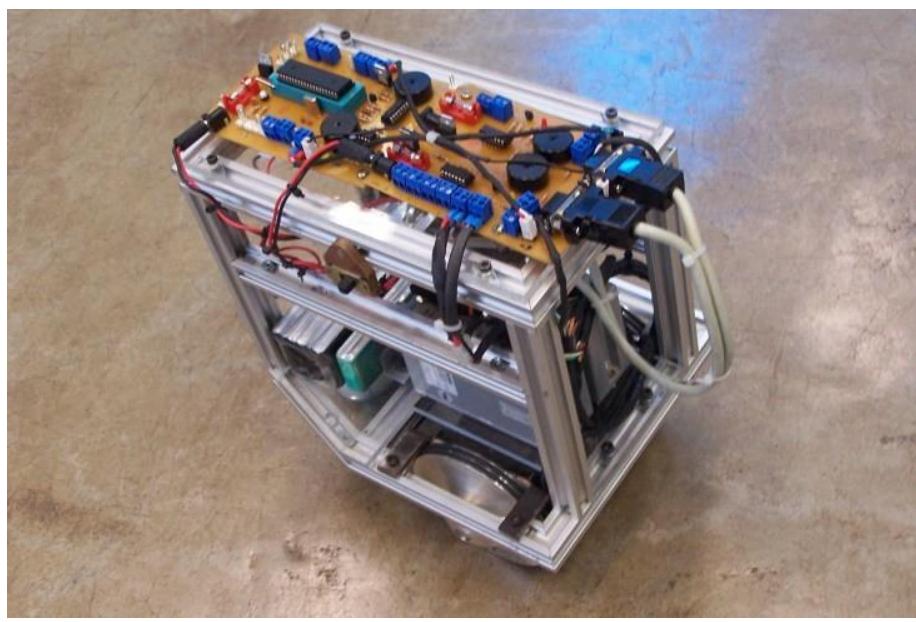

Figura 10 - Robô pronto para a navegação

\section{CONCLUSÃO}

A aplicação de microcontroladores no controle de posicionamento e repetibilidade de um robô demonstraram possuir alto desempenho, pois atendeu às necessidades do projeto.

A utilização dos drives para controle dos motores de passo foi essencial para o controle de posicionamento do robô. Com ele foi possível trabalhar com uma grande precisão.

Os motores utilizados também foram de suma importância, pois, devido ao seu alto torque, não ofereceram nenhuma resistência ao fazer o robô navegar. A integração entre os drives e os motores foi muito bem aplicada.

Quanto à utilização de placas diferentes comunicando entre si, percebeu-se ideal para trabalhar com projetos diferentes em um mesmo robô. Com as placas do microcontrolador e dos drives confeccionadas, o robô consegue navegar sem dificuldades.

A utilização de baterias de Lítio-Polímero tornou o sistema mais leve e com uma reserva de energia muito maior, se comparada à utilização de outros tipos de baterias. Dessa forma o projeto apresentou uma autonomia de até três horas continuas sem a necessidade de troca ou recarga de baterias.

O sucesso do trabalho desenvolvido traz a sugestão de um aprofundamento na pesquisa sobre a utilização de microcontroladores para diversas aplicações na área de eletroeletrônica e automação. Isso traria inovação e criação de novas tecnologias. É possível também comparar o uso de diversos microcontroladores diferentes, além de trabalhar com diversas linguagens de programação. Assim se poderá definir a melhor maneira de trabalhar com essa tecnologia e ampliar o conhecimento na área de robótica e áreas afins. 


\section{REFERÊNCIA BIBLIOGRÁFICA}

Carvalhosa, André Manuel Ferraz; LEITE, Tiago Leão Branco.Versa Robot: Robot móvel versátil para competições em provas de robótica. Cidade do Porto, (2006). Disponível em <http://paginas.fe.up.pt/ ee00011/web/Relatorio_final_VersaProject_.pdf〉. Acesso em 11 Jun. 2011. Muñoz, Nelson David.; ANDRADE, Carlos Andrés.; OSPINA, Nelson Londoño (2006). Diseño y construcción de un robot móvil orientado a La enseñanza e investigació, Ingeniería y desarrollo, $\mathrm{n}^{\circ}$ 19, PP. 114-127.

Pieri, Edson Roberto de. Curso de Robótica Móvel. Florianópolis, (2002).Disponível em: <http://www.ebah.com.br/curso-de-robotica-movel-pdf- pdf-a1742.html>. Acessado em: 11 Jun. 2011.

Silva, Renato A (2006). Programando microcontroladores PIC: Linguagem "C”, Ensino Profissional, São Paulo.

PARKER. Catálogo 6002-3 BR - Sistemas de Controle e Movimento.Jacareí. Disponívelem: <http://tecniar.com.br/downloads/parker/14_tecniar_elet romecanica.pdf>. Acesso em 06 Mai. 2011 a.

PARKER.OEM750 Drive OEM750X Drive/Indexer - User Guide. Disponível em: <http://www.parkermotion.com/manuals/OEM750/OE M750_Entire_Rev_B.pdf>. Acesso em 06 Mai. $2011 b$. 